\title{
Papilioerythrinone: A New Ketocarotenoid in Integuments of Orange Pupae of a Swallowtail, Papilio xuthus, and Carapaces of a Crab, Paralithodes brevipes (Hanasakigani in Japanesc)
}

\author{
Keiji Harashima, Jun-ichiro Nakahara and Goro Kato \\ Department of Agricultural Chemistry, The University of Tokyo, \\ Bunkyo-ku, Tokyo, Japan
}

Received September 23, 1975

\begin{abstract}
A minor carotenoid in integuments of orange pupae of a swallowtail, Papilio xuthus, was found also in carapaces of a crab, Paralithodes brevipes (hanasakigani). This new carotenoid showed a visible absorption spectrum similar to that of papilioerythrin $(=\alpha$ doradexanthin) and was named papilioerythrinone. Reduction of this compound with sodium borohydride occurred in 2 steps and gave products identical with the reduction products of papilioerythrin. Therefore, the structure 3 -hydroxy- $\beta, s-$ carotene-4, $3^{\prime}$-dione (IV) is ascribed to papilioerythrinone.
\end{abstract}

Previously ${ }^{1 /}$ we reported that the principal carotenoids in integuments of orange pupae of a swallowtail, Papilio xuthus L., were canthaxanthin and papilioerythrin (III). Small amounts of $\alpha$ - and $\beta$-carotenes, lutein (I) astaxanthin and several unidentified minor components were also found. Because of lack of materials we have not yet been able to characterize these minor pigments.

Recently we found that one of them was contained also in carapaces of a crab, Paralithodes brevipes $\mathrm{H}$. Milne Edwards et Lucas (Japanese name hanasakigani). This finding enabled us to characterize the minor carotenoid. This paper concerns the elucidation of the chemical structure of this compound, which was found to be a new ketocarotenoid and called papilioerythrinone.

\section{MATERIALS AND METHODS}

Insect. Orange pupae, male and female, of Papilio xuthus L., were prepared and supplied by Prof. T. Hidaka and Miss Keiko Yamashita, Kyoto University. Larvae of the swallowtail were reared on a semisynthetic diet containing dry powder of leaves of a rutaceous plant, Poncirus trifoliata Rafinesque, under short-day photoperiodic conditions. Pupation took place in June 1975.
Crab. Boiled and frozen specimens (male and female) of the crab, Paralithodes brevipes $\mathrm{H}$. Milne Edwards et Lucas (hanasakigani in Japanese), were purchased from the market.

Silisic acid for chromatography. Silisic acid (Mallinckrodt Chemical Works) was washed with $3 \mathrm{~N}$ hydrochloric acid, distilled water and ethanol successively, dried overnight at $135^{\circ} \mathrm{C}$ and deactivated by addition of $10 \%(w / w)$ distilled water. Columns were prepared by a wet method.

Papilioerythrin. The papilioerythrin fraction obtained from the pupal integuments ${ }^{1}$ as described in the section of REsults in this paper was dissolved in a small volume of benzene and stored under an atmosphere of nitrogen at $-20^{\circ} \mathrm{C}$ until use.

Thin-layer chromatography (TLC). Thin layers of silica gel $\mathrm{G}$ (Kieselgel $\mathrm{G}$ nach Stahl, Type 60, Merck), 0.25 or $1.0 \mathrm{~mm}$ in thickness, were used after activation at $135^{\circ} \mathrm{C}$ overnight. Development was carried out in a chamber filled with nitrogen. If necessary spots or bands were scraped off and extracted thoroughly with $1: 1(\mathrm{v} / \mathrm{v})$ mixture of benzene and methanol. The extracts were evaporated in vacuo and the residues were dissolved in small volumes of $1: 1(\mathrm{v} / \mathrm{v}) \mathrm{mixture}$ of benzene and acetone. The resulting solutions were filtered through filter paper, evaporated in vacuo and the residues were dissolved in suitable volumes of benzene for further examination.

Acetylation. Gradual acetylation was carried out as described previously ${ }^{2)}$ with acetic anhydride in pyridine. 
Reduction. Two $\mathrm{ml}$ of a sodium borohydride solution in aqueous $90 \%(\mathrm{v} / \mathrm{v})$ ethanol in a given concentration was added to $2 \mathrm{ml}$ of a carotenoid solution in benzene. The resulting solution was left to stand for a given period at a given temperature. The solution was then washed well with distilled water, evaporated in vacuo and the residue was dissolved in $2 \mathrm{ml}$ of benzene for spectroscopy or in $0.2 \mathrm{ml}$ for examination by TLC.

Alkali-treatment. Alkali-treatment was cartied out according to the method for "saponification" as reported previously."

Spectroscopy. Visible absorption spectra were recorded with a Hitachi spectrophotoneter, Model 124, equipped with a recorder, Model 056. Amounts of carotenoids were calculated as astaxanthin from light absorbancies at $487 \mathrm{~nm}$ in benzene using $E_{0}$ of astaxanthin, 1900. ${ }^{3)}$

\section{RESULTS}

\section{Isolation of the pupal minor carotenoid}

Integuments $(5.1 \mathrm{~g})$ of 38 orange pupae of the swallowtail were prepared and extracted with acetone as described previously. ${ }^{1)}$ Carotenoids extracted were transferred into $n$-hexane and the $n$-hexane solution was extracted 3 times with aqueous $95 \%(\mathrm{v} / \mathrm{v})$ methanol. The hypophasic aqueous methanol solutions were combined and extracted with benzene after being diluted with an equal volume of distilled water. The extract was washed 3 times with an aqueous saturated solution of sodium chloride, dried over anhydrous sodium sulfate and evaporated in vacuo. The residue was dissolved in $0.2 \mathrm{ml}$ of benzene and submitted to TLC on a thin-layer plate of $1 \mathrm{~mm}$ in thickness. The epiphasic solution was also dried over anhydrous sodium sulfate and evaporated in vacuo. The residue was dissolved in $0.2 \mathrm{ml}$ of $n$-hexane and submitted to TLC on a thinlayer plate of $1 \mathrm{~mm}$ in thickness.

Figure 1-A illustrates the chromatographic profiles of the epiphasic and hypophasic fractions of pupal carotenoids. The epiphasic fraction contained $\alpha$ - and $\beta$-carotenes, canthaxanthin and an unidentified minor component. The hypophasic fraction contained canthaxanthin, astaxanthin, papilioerythrin, lutein and 3 minor components. The most abundant of them (P-5) was the one this paper concerns. It was eluted from the corresponding spot and rechromatographed on a silica gel $\mathrm{G}$ plate $(0.25 \mathrm{~mm}$ in thickness). Triple development with $n$-hexane-benzene-methanol 16:6:1 (v/v/v) for $16 \mathrm{~cm}$ gave a chromatographically pure fraction of P-5 which was finally dissolved in $2 \mathrm{ml}$ of benzene and sub-<smiles>CC1=CC(O)CC(C)(C)C1/C=C/C(C)=C/C=C/C(C)=C/C=C/C=C(C)/C=C/C=C(C)/C=C/C1=C(C)CC(O)CC1(C)C</smiles>

I

lutein

$\downarrow 0$<smiles>CC1=CC(O)CC(C)(C)C1/C=C/C(C)=C/C=C/C(C)=C/C=C/C=C(C)/C=C/C=C(C)/C=C/C1=C(C)C(=O)C(O)CC1(C)C</smiles>

III

papilioerythrin<smiles>CC1=CC(O)CC(C)C1/C=C/C(C)=C/C=C/C(C)=C/C/C=C(C)/C=C/C=C(C)/C=C/C1=C(C)C(O)C(O)CC1(C)C</smiles>

VI

reduced papilioerythrin

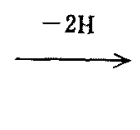<smiles>CC1=CC(=O)CC(C)(C)C1/C=C(C)/C=C(C)/C=C/C(C)=C/C=C/C=C(C)/C=C/C=C(C)/C=C/C1=C(C)CC(O)CC1(C)C</smiles>

II philosamiaxanthin<smiles>CCCO</smiles><smiles>CCC</smiles><smiles>CC(C=CC=CC=C(C)C=CC=C(C)C=CC1CC(C)C(=O)C=C1C)=CC=CC=C(C)C=CC1=C(C)C(C)(C)CC(O)C1=O</smiles>

IV

papilioerythrinone<smiles>[10BH2]NC1CC1</smiles>

$\mathrm{NaBH}_{4}$<smiles>CC1=CC(=O)CC(C)(C)C1/C=C(C)/C=C(C)/C=C(C)/C=C/C=C/C(C)=C/C=C/C=C(C)\C=C(/C)C1(C)CC(O)C(O)C(C)=C1C</smiles>

4-hydroxyphilosamiaxanthin 


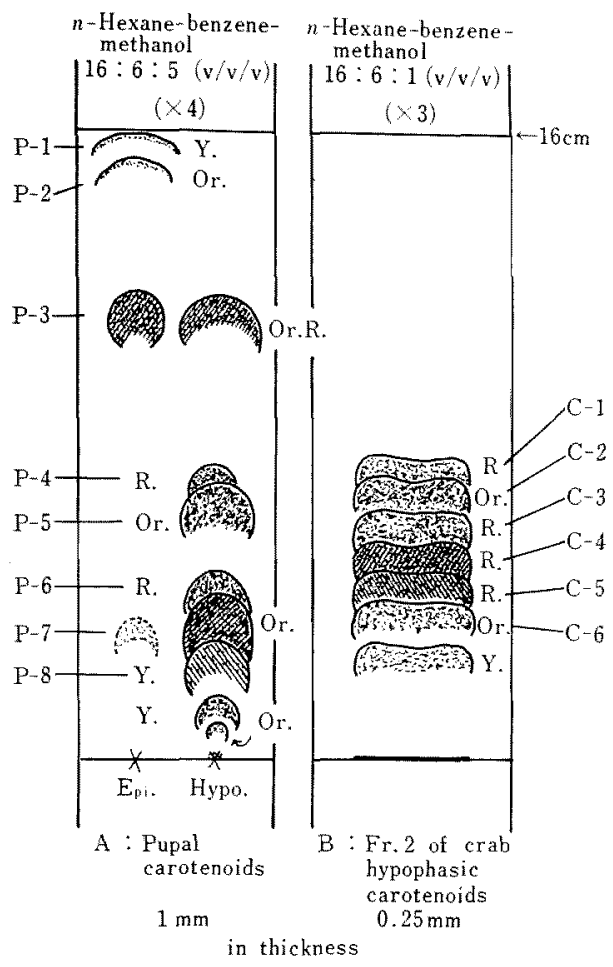

Fig. 1. Thin-layer Chromatograms of the Pupal and Fr. 2 of the Crab Hypophasic Carotenoids.

Epi., epiphasic fraction; Hypo, hypophasic fraction. $\mathbf{P}-1$, carotenes; $\mathbf{P}-2$, unidentified; $\mathbf{P}-\mathbf{3}$, canthaxanthin; $\mathbf{P}-4$, unidentified; $\mathbf{P}-5$, the minor component in question; $\mathrm{P}-6$, astaxanthin; $\mathrm{P}-7$, papilioerythrin; $\mathrm{P}-8$, lutein.

$\mathrm{C}-1$, unidentified; $\mathrm{C}-2$, the minor component in question; $\mathrm{C}-3$, unidentified, the band was not clear; $\mathrm{C}-4$, an unknown pigment; $\mathrm{C}-5$, astaxanthin; $\mathrm{C}-6$, a papilioerythrin-like pigment.

mitted to further examination. Light absorbancy of this solution at $465 \mathrm{~nm}\left(\lambda_{\max }\right)$ was 0.359 .

The papilioerythrin fraction was obtained from the spot P-7 and used for the authentic sample.

\section{Isolation of the crab minor carotenoid}

Carapaces were stripped off the bodies of 4 specimens of the crab, washed well with water and thoroughly cleaned of hypodermis. After being half-dried in air at room temperature overnight the carapaces $(670 \mathrm{~g})$ were extracted 3 times with 1.5 liter portions of acetone in a refrigerator. The acetone solutions were combined and the combined solu- tion was extracted 3 times with 1.5 liter portions of benzene after being diluted with an equal volume of distilled water. The extracts were combined and washed well with an aqueous saturated solution of sodium chloride, dried over anhydrous sodium sulfate and evaporated in vacuo. The residue was partitioned between $n$-hexane and aqueous $95 \%$ $(\mathrm{v} / \mathrm{v})$ methanol. The epiphasic layer was further extracted twice with $95 \%$ methanol. The hypophasic solutions were combined and the combined solution was extracted with benzene after dilution with an equal volume of distilled water. The extract was dried over anhydrous sodium sulfate, evaporated in vacuo and the residue was dissolved in $6 \mathrm{ml}$ of benzene. Addition of $30 \mathrm{ml}$ of $n$-hexane to the solution and cooling at $-20^{\circ} \mathrm{C}$ overnight yielded $20 \mathrm{mg}$ of crude crystals of astaxanthin, which were recrystallized 3 times from pyridine-benzene-n-hexane. The mother liquors obtained in the second and third recrystallizations were combined and evaporated in vacuo. The residue was dissolved in $5 \mathrm{ml}$ of benzene and submitted to fractionation by repeated chromatography on columns of silisic acid followed by repeated TLC.

The benzene solution obtained as described above containing a total of $3.5 \mathrm{mg}$ of carotenoids was loaded onto the first column $(25.5 \times$

Table I. Elution Pattern of the Crab Hypophasic CaRotenoIdS FROM THE FIRST Column of Silisic Acid

\begin{tabular}{|c|c|c|c|}
\hline $\begin{array}{l}\text { Fraction } \\
\text { No. }\end{array}$ & $\begin{array}{cc}\text { Colour } & C \\
\text { of } & \text { of } \\
\text { band } & \text { in }\end{array}$ & $\begin{array}{l}\text { Concentration } \\
\text { of acetone }(\%) \\
\text { in } n \text {-hexane }(v / v)\end{array}$ & $\begin{array}{l}\text { Main carotenoids } \\
\text { contained }\end{array}$ \\
\hline 1 & Red & 4 & Unidentified $(\mathrm{C}-1)$ \\
\hline 2 & Orange red & $\begin{array}{l}2 \\
\mathrm{c} \\
\mathrm{C}\end{array}$ & $\begin{array}{l}2 \text { or } 3 \text { unknown } \\
\text { components }(\mathrm{C}-2 \text {, } \\
\mathrm{C}-3 \text { ? and } \mathrm{C}-4)\end{array}$ \\
\hline 3 & Deep red & $\begin{array}{l}A \\
\mathrm{p} \\
\mathrm{x} \\
\mathrm{a} \\
\mathrm{p}\end{array}$ & $\begin{array}{l}\text { An unknown com- } \\
\text { ponent (C-4), asta- } \\
\text { xanthin (C-5) and } \\
\text { a papilioerythin-like } \\
\text { pigment }(\mathrm{C}-6)\end{array}$ \\
\hline 4 & Red orange & $\begin{array}{l}\text { A } \\
\text { a } \\
\text { li }\end{array}$ & $\begin{array}{l}\text { Astaxanthin }(C-5) \\
\text { and a papilioerythin- } \\
\text { like pigment }(C-6)\end{array}$ \\
\hline
\end{tabular}




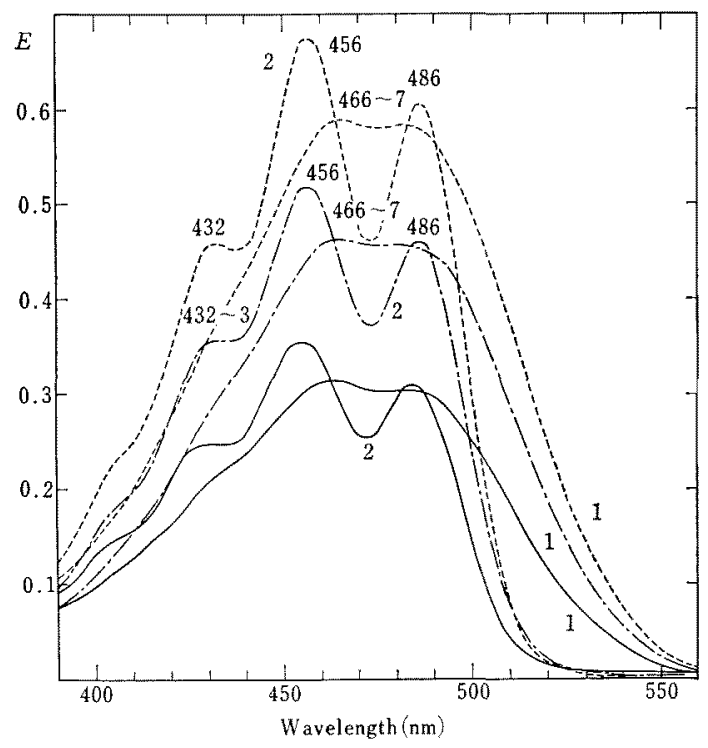

Fig. 2. Visible Absorption Spectra of $\mathbf{P}-5$ and $\mathbf{C}-2$ in Benzene.

-, P-5;-.-.--, C-2; -.---, papilioerythrin.

1, before reduction; 2, after reduction with $\mathrm{NaBH}_{4}$.

$100 \mathrm{~mm}$ ), which was then washed with $3 \%$ $(\mathrm{v} / \mathrm{v})$ acetone in $n$-hexane. Minute amounts of several unidentified components were eluted. When the column was further washed with $4 \sim 7 \%$ acetone in $n$-hexane 4 fractions were obtained. The elution pattern is shown in Table I. Examination of these fractions by TLC revealed the constitutions listed in this table. A large amount of astaxanthin (C-5) was found in Fr. 3 which contained also an unknown deep red pigment (C-4) and a papilioerythrin-like pigment, the main component (C-6) of Fr. 4. The pigment this paper concerns (C-2) was contained in Fr. 2. Rechromatography of this fraction containing a total of $0.92 \mathrm{mg}$ of carotenoids on the second column $(16.90 \mathrm{~mm})$ gave a partially purified fraction containing a total of $0.21 \mathrm{mg}$ of carotenoids. TLC of this fraction on a silica gel $G$ plate $(0.25 \mathrm{~mm}$ in thickness) gave the chromatogram shown in Fig. 1-B. Beside the band of C-2, five or six bands were still observed. The band between $\mathrm{C}-2$ and $\mathrm{C}-4$ bands was not clear. The pigment $\mathrm{C}-4$ was found more abundantly than $\mathrm{C}-2$.

Elution of the $\mathrm{C}-2$ band followed by re-

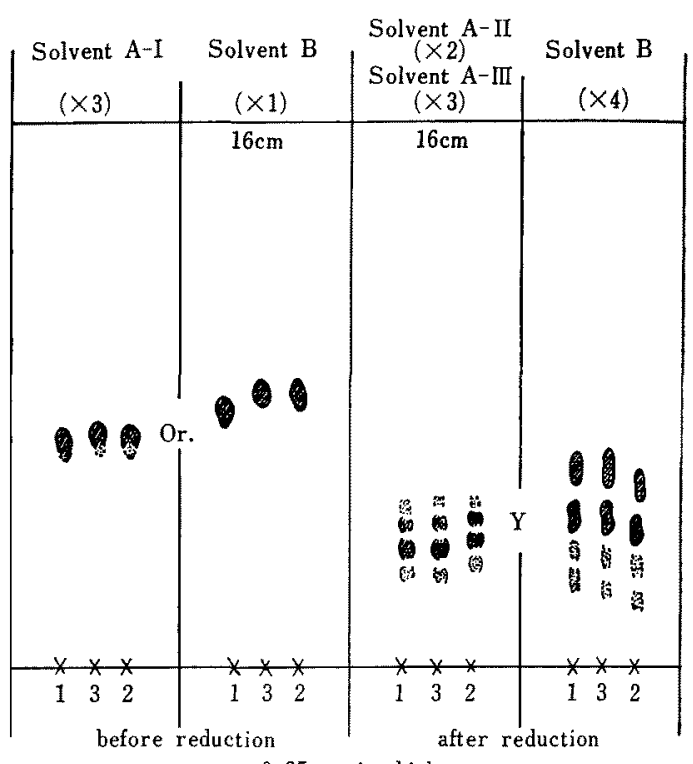

$0.25 \mathrm{~mm}$ in thickness

Fig. 3. Thin-layer Chromatograms Showing Identity of $\mathrm{P}-5$ and $\mathrm{C}-2$.

Solvents for development were

A-I: $n$-hexane-benzene-methanol $16: 6: 1 \quad(\mathrm{v} / \mathrm{v} / \mathrm{v})$, A-II: $n$-hexane-benzene-methanol $10: 15: 1(\mathrm{v} / \mathrm{v} / \mathrm{v})$, A-III: $n$-hexane-benzene-methanol $20: 30: 3(\mathrm{v} / \mathrm{v} / \mathrm{v})$ and $\mathrm{B}$ : acetone-benzene $1: 8$.

1: $\mathrm{C}-2,2: \mathrm{P}-5,3$ : a mixture of $\mathrm{C}-2$ and $\mathrm{P}-5$.

Colours of spots were orange (Or.) and yellow (Y.).

peated TLC on silica gel $\mathrm{G}$ plates $(0.25 \mathrm{~mm}$ in thickness) yielded about $90 \mu \mathrm{g}$ of this pigment dissolved in a small volume of benzene.

Identity of the pupal pigment, $P-5$, and the crab pigment, $\mathrm{C}-2$

Figure 2 shows absorption spectra of pupal P-5 and crab C-2. The absorption spectrum of P-5 closely resembled those of C-2 and papilioerythrin. Reduction of both compounds with sodium borohydride gave products showing spectra similar to that of lutein or reduced papilioerythrin.

Figure 3 shows chromatograms of P-5 and C-2. Both pigments showed the same $R f$ values before and after borohydride-reduction.

Therefore, P-5 was assumed to be identical with $\mathrm{C}-2$ and further characterization of this carotenoid was carried out with $\mathrm{C}-2$ isolated from the crab carapaces. 


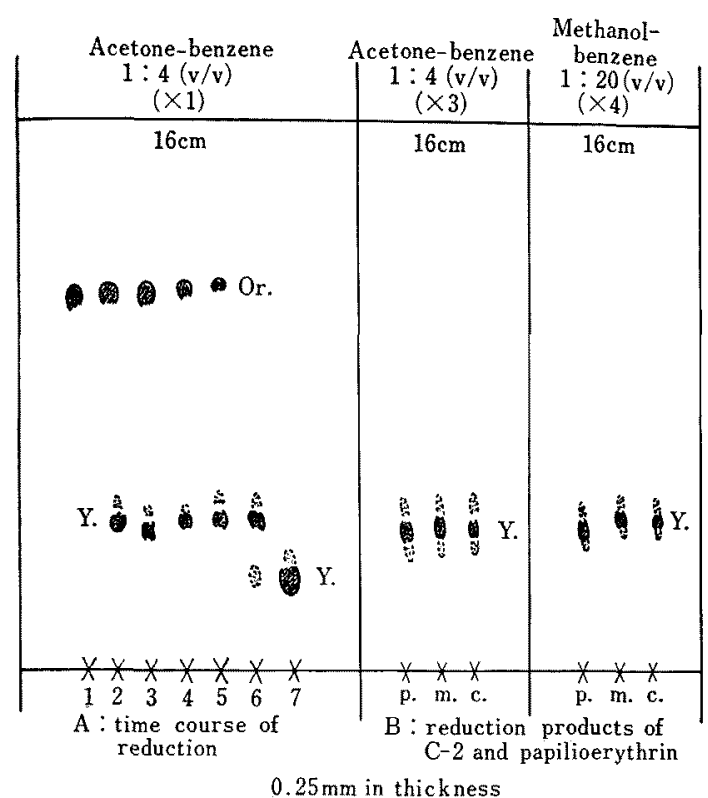

FIg. 4. Thin-layer Chromatograms Showing Profile of Reduction of $\mathrm{C}-2$ with Sodium Borohydride.

A: The pigment $\mathrm{C}-2$ was reduced under various conditions. $1,2,3,4,5$ and 6 : reduction with $0.1 \%$ solution of $\mathrm{NaBH}_{4} . \quad 1: 0 \mathrm{~min}, 2: 30 \mathrm{~min}, 3: 60 \mathrm{~min}, 4: 120 \mathrm{~min}$ and 5: $180 \mathrm{~min}$ in an ice bath, $6: 240 \mathrm{~min}$ at $18^{\circ} \mathrm{C}$. 7: reduction with $1 \%$ solution of $\mathrm{NaBH}_{4}$ at $18^{\circ} \mathrm{C}$ for $60 \mathrm{~min}$.

B: Papilioerythrin and $\mathrm{C}-2$ were reduced with $1 \%$ solution of $\mathrm{NaBH}_{4}$ for $60 \mathrm{~min}$ at $18^{\circ} \mathrm{C}$. p., reduction products of papilioerythrin; $\mathrm{c}$., reduction products of $\mathrm{C}-2 ; \mathrm{m}$., a mixture of $\mathrm{p}$. and $\mathrm{c}$.

Colours of spots were orange (Or.) and yellow (Y.).

\section{Chemical structure of $\mathrm{C}-2$}

As already mentioned in the previous paragraph, C-2 showed an absorption spectrum similar to that of papilioerythrin (III) and the reduction with sodium borohydride caused a change of the spectrum quite similar to that in the case of papilioerythrin (III) ${ }^{1}$ (Fig. 2). Consequently the chromophore in the molecule of this compound seems to be the same as that in the papilioerythrin molecule and reduced C-2 is assumed to have the same chromophore as that of reduced papilioerythrin (VI).

Figure 4-A shows that the reduction of $\mathrm{C}-2$ occurred in 2 steps. The first step proceeded even in an ice bath with borohydride in low concentration $(0.1 \%)$. The second step proceeded at $18^{\circ} \mathrm{C}$ with borohydride in high con-

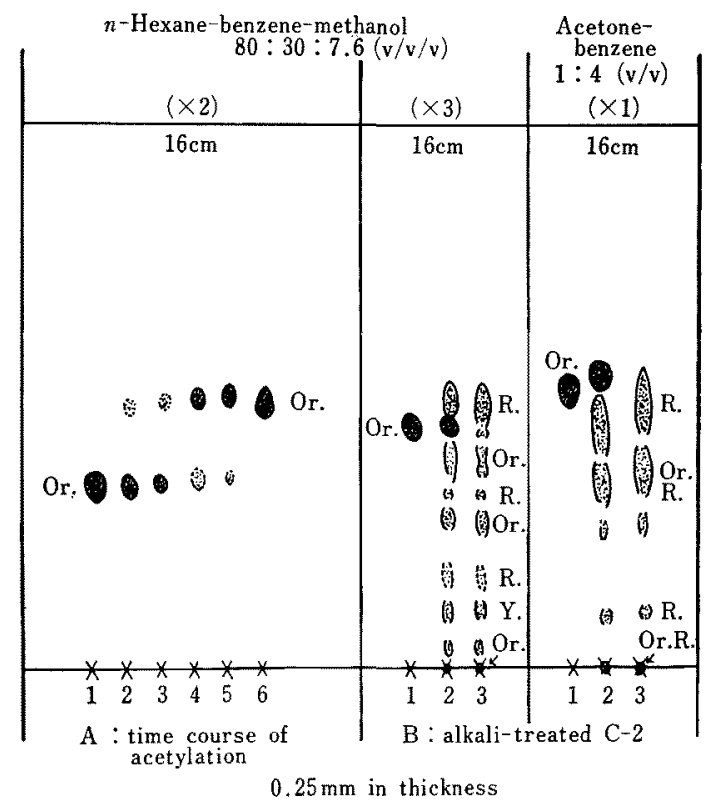

Fig. 5. Thin-layer Chromatograms Showing Time Course of Acetylation and Alkali-lability of $\mathrm{C}-2$.

A: The pigment $\mathrm{C}-2$ was acetylated with acetic anhydride in pyridine for

1: $0 \mathrm{~min}, 2: 10 \mathrm{~min}, 3: 30 \mathrm{~min}, 4: 60 \mathrm{~min}, 5: 120 \mathrm{~min}$ and $6: 19.5 \mathrm{hr}$.

B: The pigment $\mathrm{C}-2$ was treated with $\mathrm{KOH}$ overnight at room temperature. $1: \mathrm{C}-2,2:$ a mixture of $\mathrm{C}-2$ and alkali-treated $\mathrm{C}-2$, and 3 : alkali-treated $\mathrm{C}-2$.

Colours of spots were orange (Or.), red (R.), orange red (Or. R.) and yellow (Y.).

centration $(1 \%)$. The spectral change was accomplished during the first step of the reduction. Therefore 2 carbonyl groups of different types must be present in this carotenoid molecule. Since the reaction rate of the first step of the reduction is comparable to the reduction rate of papilioerythrin (III) ${ }^{1}$ and the rate of the reduction of the second step is comparable to that of philosamiaxanthin (II), ${ }^{2)}$ it is assumed that one of the 2 carbonyl groups is present as an $\alpha$-ketol group and the other as an ordinary carbonyl group. On the other hand the reduction products of $\mathrm{C}-2 \mathrm{did}$ not separate from those of papilioerythrin on a silica gel G plate (Fig. 4-B). Thus the reduction of $\mathrm{C}-2$ afforded products identical with the reduction products of papilioerythrin, namely trihydroxy- $\alpha$-carotenes (VI). Of the 2 possible structures giving trihydroxy- $\alpha$ - 
carotenes (VI) by reduction, $3^{\prime}$-hydroxy- $\beta, \varepsilon-$ carotene-3,4-dione ( $\alpha$-doradecin) is ruled out because of the difference in the absorption

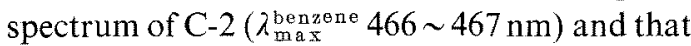
of $\alpha$-doradecin ( $\lambda_{\mathrm{max}}^{\mathrm{ben} z \operatorname{man}} 482 \sim 484 \mathrm{~nm}$ ). Therefore, the structure 3-hydroxy- $\beta, \varepsilon$-carotene- 4,3 ' dione (IV) is proposed as the most probable structure of this carotenoid and the product of the first step of the reduction is assumed to be 3,4-dihydroxy- $\beta, \varepsilon$-carotene- $3^{\prime}$-one (V).

This proposed structure is substantiated by the acetylation reaction with acetic anhydride in pyridine and by the alkali-lability of this compound. As in the case of philosamiaxanthin (II), ${ }^{2}$ treatment of this compound with potassium hydroxide overnight under the conditions for saponification caused degradation of the molecule resulting in the formation of several products of different colours (Fig. 5-B). Thus the presence of a carbonyl group at $3^{\prime}$-position of $\alpha$-ring is confirmed. This property also excluded the possibility of the identity of C-2 with $\alpha$-doradecin which can be produced by alkali-treatment of papilioerythrin in the presence of oxygen. Figure 5-A shows that acetylation with acetic anhydride occurred in one step. This fact is also compatible with the proposed structure (IV). Thus the structure 3-hydroxy- $\beta, \varepsilon$-carotene-4,3'-dione (IV) is most likely ascribed to $\mathrm{C}-2$, as well as P-5, which may be formed from papilioerythrin (III) by dehydrogenation in organisms. Therefore we propose the trivial name of this carotenoid, papilioerythrinone.

\section{DISCUSSION}

Papilioerythrin ( $=\alpha$-doradexanthin) (III) is the carotenoid most abundantly found in integuments of orange pupae of the swallowtail, $P$. xuthus, and seems to be formed in the body of the insect by oxidation of lutein (I). ${ }^{1}$, On the other hand philosamiaxanthin (II) is found in haemolymph of a silk worm, Philosamia cynthia, ${ }^{2 \prime}$ and seems to be derived also from lutein (I). Papilioerythrin has a carbonyl group at the 4-position and philosamiaxanthin has a carbonyl group at the 3 -position.
Therefore, presence of a 4,3'-diketo compound derived from lutein was expected. Moreover philosamiaxanthin is sometimes found in integuments and haemolymph of diapausing green pupae of the swallowtail." Accordingly, the finding of papilioerythrinone (IV) in integuments of orange pupae of this insect is not surprising.

Because papilioerythrinone can be formed from papilioerythrin in organisms, other organisms containing a considerable amount of papilioerythrin may contain also a small amount of papilioerythrinone. Carapaces of this crab, $P$. brevipes, contained a considerable amount of a papilioerythrin-like carotenoid (C-6). Four other crabs, P. camtschaticus Tilesius (Alaska king crab), Erimacrus isenbeckii (kegani in Japanese), Chinoecetes japonicus (benizuwaigani in Japanese), Portunus trituberculatus Miers (gazami in Japanese) and a prawn, Penaeus japonicus Bate (kurumaebi in Japanese), contained neither papilioerythrin nor papilioerythrinone.

Because papilioerythrinone, as well as philosamiaxanthin, is alkali-labile, saponification must be avoided for detection of these carotenoids. Matsuo and Watanabe, ${ }^{5}$ who reported the presence of large amounts of papilioerythrin in carapaces of Sesarma haematocheir (akategani) and $S$. intermedia (benkeigani), did not detect papilioerythrinone. Because they saponified lipids of the carapaces prior to chromatographic fractionation of carotenoids, papilioerythrinone, if present, might be degraded. Re-examination may be needed. It is also true for the analysis of carotenoids of many fishes containing esters of papilioerythrin, for example gold fish ${ }^{6}$ and sea bream. ${ }^{\text {? }}$

Papilioerythrinone (IV) is assumed to be formed from lutein (I) in orange pupae of the swallowtail. However, it is not certain whether papilioerythrin (III) is the intermediate of papilioerythrinone (IV) formation or not. Since philosamiaxanthin (II) is sometimes found in a small amount in green diapausing pupae, ${ }^{4)}$ the possibility cannot completely be ruled out that philosamiaxanthin (II) is the 
intermediate.

The principal carotenoid in carapaces of the crab, $P$. brevipes, is astaxanthin, as in the case of many other crabs and lobsters. Beside astaxanthin, a considerable amount of a papilioerythrin-like pigment was found. Other unidentified minor components were also present, one of which (C-4) seemed to be a new pigment. Although we used boiled carapaces as starting material, not even a minute amount of astacene was detected. This is true for all samples examined. Sometimes colours of boiled lobsters and $\mathrm{crabs}^{\mathrm{s}}$ have been attributed to presence of astacene formed by oxidation of astaxanthin liberated by heating from astaxanthin-protein complexes. However, our results show astaxanthin in crab- and prawn-carapaces is not oxidized into astacene by heating in the absence of alkali.

Further experiments to confirm the proposed structure of papilioerythrinone are now in progress. The total analysis of the carotenoids in carapaces of this crab, $P$. brevipes will be reported in the near future.
Acknowledgement. This work was undertaken in collaboration with Prof. Toshitaka Hidaka and Miss Keiko Yamashita, Kyoto University, to whom we are indebted for the supply of the orange pupae of the swallowtail. We wish to express many thanks to Prof. Takashi Hibiya and Dr. Katsumi Yamaguchi, The University of Tokyo, for their kind advice and to Prof. Michinori Nakamura and colleagues, The University of Tokyo, for their helpful discussion.

\section{REFERENCES}

1) K. Harashima, T. Ohno, T. Sawachika, T. Hidaka and E. Ohnishi, Insect Biochem, 2, 29 (1972).

2) K. Harashima, Int. J. Biochem., 1, 523 (1970).

3) T. Kanemitsu and H. Aoe, Nippon Suisan Gakkaishi, 24, 209 (1958).

4) K. Harashima, T. Ohno, T. Sawachika, T. Hidaka and E. Ohnishi, Proc. Japan. Conference Biochem. Lipids, 13, 111 (1971).

5) T. Matsuo and T. Watanabe, Nippon Suisan Gakkaishi, 40, 767 (1974).

6) T. Katayama, H. Yokoyama and C.O. Chichester, Int. J. Biochem., 1, 438 (1970).

7) T. Katayama, K. Hirata, H. Yokoyama and C. O. Chichester, Nippon Suisan Gakkaishi, 36, 709 (1970).

8) B. C. L. Weedon, "Carotenoids," ed. by O. Isler, Birkhäuser Verlag, Basel, 1971, p. 39. 